\title{
SEPARATENESS AND TOGETHERNESS: INTERDEPENDENCE OVER THE LIFE COURSE IN JAPANESE AND AMERICAN MARRIAGES
}

\author{
Berit Ingersoll-Dayton \& Ruth Campbell
}

The University of Michigan

Yukiko Kurokawa \& Masahiko Saito

Tokyo University Hospital

\begin{abstract}
This study examines cross-cultural conceptions of interdependence within marriage over the life cycle. Older Japanese and American couples participated in a narrative interview in which both spouses jointly discussed the story of their marriage. The resulting data were analyzed qualitatively and several salient themes emerged. Interdependence among couples varied across cultures and between racial groups. Further, the couples' feelings of intimacy and distance were renegotiated over the life course. The implications of these findings are discussed in relation to family development theory.

KEY WORDS $\bullet$ cross-cultural $\bullet$ life span $\bullet$ marital relationships
\end{abstract}

The growth of the aging population in the US and Japan has had a profound impact on the family life cycle, especially on marital relationships in both countries. Increasing life expectancy has expanded the duration of years that spouses spend together. Japan now has the highest life expectancy in the world (Kono, 1994). Kumagai (1984) estimates that for Japanese couples, the 'postparental period in Japan is almost equivalent to one third of their total married years' (p. 202). Similarly, in the US, marriage into later life is increasingly prevalent, such that 54 percent of people over the age of 65 years live in couple households (Schick \& Schick, 1994).

Gilford (1986) notes that, because long-term marriages are such a new

The authors would like to thank Mary Mengel for her invaluable assistance with the data management and Hilary Robinson for her help with the graphics. Address correspondence to Berit Ingersoll-Dayton, School of Social Work, 1065 Frieze Building, University of Michigan, Ann Arbor, MI 48109-1285, USA. bid@umich.edu

Journal of Social and Personal Relationships $(1) 1996$ SAGE (London, Thousand Oaks, CA and New Delhi), Vol. 13(3): 385-398. 
phenomenon historically, older couples have few role models and inadequate preparation for coping with the stresses associated with later life. She contends that: 'Although some couples may have built reserves of intimacy and belongingness on which to draw, other couples may find their interdependency in late life to be inequitably distributed, burdensome and a source of conflict' (p. 19).

At present, we have little knowledge about the life-course experiences of aged couples. Patterns of interdependence may differ quite markedly for couples over time and across cultures. This article examines conceptions of marriage among older couples in Japan and the US with respect to their interdependence.

To understand the differences between long-term American and Japanese marriages, it is necessary to look at the unique historical and structural context of the traditional Japanese family system. Marriage in Japan was traditionally rooted in the 'ie' or 'household' and was a contract between families, not an agreement between individuals (Blood, 1967). The prewar Civil Code enacted in the Meiji Period (1868-1912) was based on the pattern of succession practiced by the samurai class in the feudal era in which direct descent in an extended family, usually through the eldest sons, preserved the existence of the family (Yuzawa, 1994). Every Japanese was listed in the register of the family to which he or she belonged. When a woman married, her name was deleted from her birth family register and she became officially registered into her husband's family. Authority was in the hands of the head of the family, who had to approve of most decisions, including marriage and divorce. In traditional Japanese families, most of the marriages were 'arranged' (Yuzawa, 1994). That is, couples met for the first time at a formal introduction arranged by a go-between and, with the families' approval, married shortly thereafter.

The 'ie' was generally composed of three generations who lived together (i.e. the elderly parents, their son and daughter-in-law and their grandchildren) and also included deceased ancestors. The traditional role of the woman in the 'ie' is characterized by the expression "ryosai-kenbo", the good wife and wise mother' (Iwao, 1993: 19). Her duties included bearing and rearing children, serving her husband and attending to the needs of her extended family, especially her parents-in-law.

Comparing long-term marriages within Japan to those within the US gives insight into the development of marital relationships and identifies those processes that are culturally unique and those that are culturally transcendent. While there is a growing body of literature on the marriages of older couples in the US, there are few comparable data on the experiences of older Japanese couples. Based upon studies of aged American couples, there is a clear indication that the elderly turn to their spouses during times of need (Coward et al., 1992). However, husbands and wives may encounter challenges such as poor health that affect their ability to maintain a balance between giving and receiving care (Kuypers \& Bengtson, 1990). Likewise, retirement can precipitate a need to reconsider the allocation of marital roles (Brubaker, 1985). This constellation of later-life events has 
implications for the ways in which couples negotiate their mutual interdependence over time.

In one of the few studies examining both Japanese and American marriages, Blood (1967) drew some sharp contrasts. He contended that, due to the segregated roles of Japanese husbands and wives, Japanese marriages were more asymmetrical and less egalitarian than American marriages. $\mathrm{He}$ also observed some important similarities between the marriages of Japanese and Americans. One similarity was that time had a corrosive influence on marriage; couples in both countries became progressively more disenchanted with their marriages over time. However, it is important to note that conclusions from this classic study are based on a sample of younger couples who had been married for 5-15 years. Our research expands upon this early study by examining the views of Japanese and American couples in long-term marriages. The purpose of this investigation was to explore the ways in which couples negotiated and renegotiated their relationships as they traveled through the life course together.

\section{Methods}

The present study used a qualitative methodology based on a narrative approach. A narrative approach involves gathering information about the stories of individuals' lives and subsequently content-analyzing these stories for distinct patterns and themes. The study of narratives crosses the boundaries between disciplines and has become recognized by social scientists as a valid approach to studying the social and cultural life of research participants (Riessman, 1993).

A narrative approach was particularly well suited to the primary focus of our investigation, that is couples' perceptions of their relationships over time. Berger \& Kellner (1964) provide some sound theoretical support for such an approach by describing how marriage represents a symbolic conversation during which spouses make meaning of their past, present and future. Our research interview simulated this conversation by encouraging spouses to tell a joint story of their marriage over the life course - a methodology which, for several reasons, is especially appropriate for our study population of older couples. First, older people comfortably and spontaneously engage in the process of reminiscence (Butler, 1980-81; Sherman, 1991). Second, story-telling is a natural way of communicating both cross-culturally and intra-culturally. Watanabe (1993) points out that, when asked a question, Japanese tend to frame their explanations as stories with details presented in a chronological order. Similarly, among African-Americans, a story-telling format is particularly consistent with their representations of reality (Heath, 1983). Third, participating in a joint narrative allows married couples to illustrate the ways in which they communicate between themselves and negotiate their differences.

Drawing on narrative methodology, Veroff et al. (1993) developed an approach which they applied successfully to African-American and white newly married couples in the US. Their approach used a 'storyboard', a visual cue presented to couples to elicit discussion of key events in their relationship (e.g. their first meeting, their decision to get married) and to help couples make 'meaning out of the flow of their relationship history' (Veroff et al., 1993: 441). 


\section{FIGURE 1}

\section{Storyboard used in marital interviews}

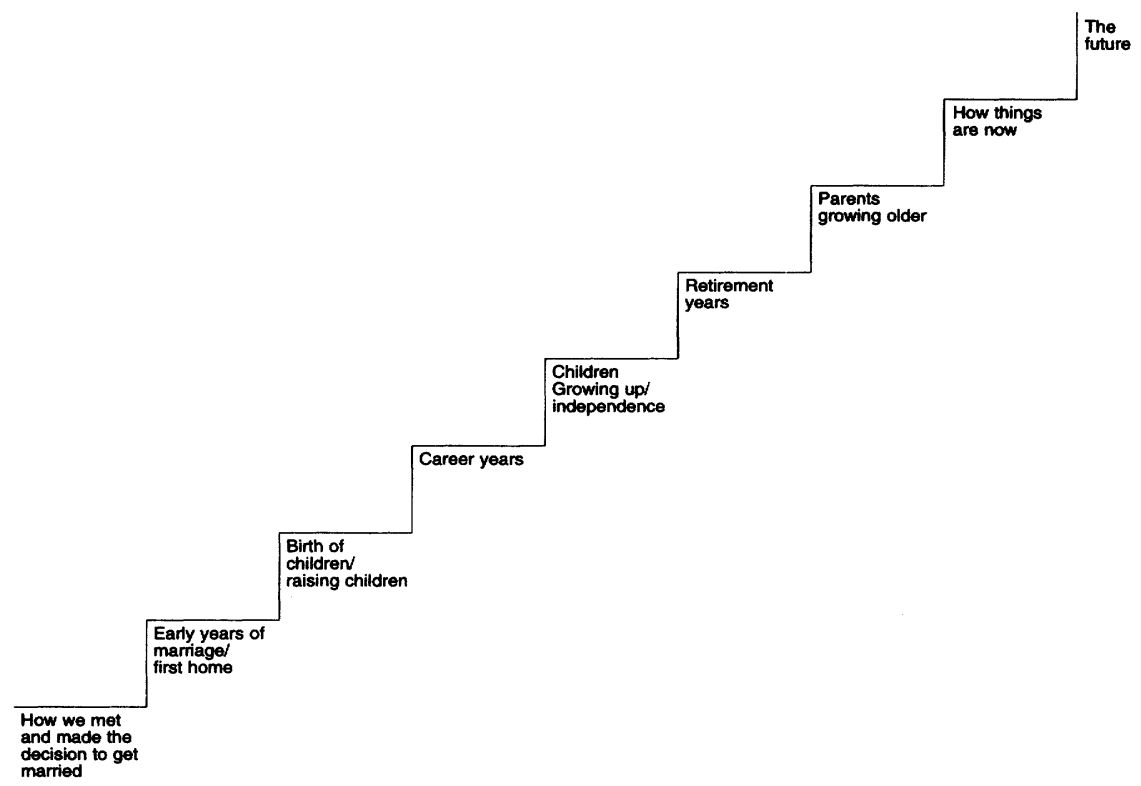

We augmented the original storyboard to include several key events experienced by couples over the life course (e.g. children growing up, retirement). The storyboard used in our interviews appears in Figure 1.

In Japan and the US, interviews were conducted with both spouses present. Four interviewers participated in this project. Each had a degree in psychiatry, psychology or social work. The American interviewers (the first two authors of this article) conducted the interviews in English with the American couples and the Japanese interviewers (the second two authors of this article) conducted the interviews in Japanese with the Japanese couples.

Interviews were generally conducted over two sessions (lasting from 1 to 2 hours each). During the first interview, after obtaining some basic demographic information, interviewers asked couples to tell the story of their relationship from the time when they first met and to address the key life-course events displayed on the storyboard. During the second interview, couples were asked to reflect further over their lives together and to discuss such issues as turning points in their marriages, the most important aspects of their marriages and changes in gender roles within their marriages.

Our purposive sample of 11 Japanese and 13 American couples was gathered in several ways. We initially developed a list of patients in a geriatric clinic, couples known to or referred to the researchers and couples who responded to advertisements about the research project. To obtain some diversity within our sample, we stratified participants on the basis of several characteristics that might influence their experience of marriage over the life course. Specifically, we stratified our pool on the basis of age, race (for the American couples), health and socioeconomic status. We then purposively selected from the pool those couples who represented diversity on these characteristics. Of the 27 couples 
contacted, 24 couples agreed to participate. The three couples who refused were either too busy to participate or in poor health or not interested.

Among the 11 Japanese couples, the average age for women was 66 years (range 54-74) and for men 70 years (range 60-77). On average, these couples had been married for 43 years; eight of the marriages had been arranged. The couples had an average of two children (ranging from one to three) and six of the couples lived with one of their children. Their mean years of education was 12 and they represented a variety of white-collar (e.g. teacher, engineer, pastor, civil servant) and blue-collar (e.g. carpenter, butcher, police officer) occupations. Most of the women had been full-time housewives. The couples' selfassessed health ranged from poor to excellent with an average of fairly good.

Among the 13 American couples, the average age for women was 73 years (range 62-87) and for men 77 years (range 68-89). Three of the couples were African-American; the remainder were white. On average, the couples had been married for 47 years and had two children; one couple had never had children and the other couples had from one to five children. The mean level of education among these couples was 14 years and they represented both whitecollar (e.g. teacher, administrator, salesman, chemist) and blue-collar (e.g. custodian, cook, carpenter, housekeeper) occupations. Most of the women had worked for significant periods of time after their marriage. A few left paid employment for several years when their children were at home and later returned to the labor force. The self-assessed health of these couples ranged from poor to excellent with an average of fairly good.

All interviews were tape-recorded and transcribed. The Japanese interviews were subsequently translated into English. Based on a preliminary content analysis of the first several interviews, the four authors mutually developed a coding scheme with topics related to the couples' ideas about their marriage, their marital relationship over time, their extended families and the manner in which the couples communicated. Responsibility for the coding of the interviews was shared by the four authors. Each interview was coded by two of the authors (one Japanese and one American). Each author coded for meaningunits relevant to the coding scheme. While coding decisions about relevant meaning-units were fairly consistent, there was less consistency with respect to the length of the meaning-unit. When inconsistency concerning the length of the meaning-units emerged (e.g. three lines of text as compared with six lines of text) the decision rule was to enter the longer meaning-unit. The Ethnograph (Seidel et al., 1988), a software package designed for interview data, was used to organize the interview content so that narrative data relevant to specific codes could be easily retrieved and examined.

Findings for this paper were systematically summarized based on several analytic steps. First, the content of the different codes was examined by the first two authors and four codes were identified as having particular relevance to this paper: independence/dependence within the marriage; intimacy/distance within the marriage; marital roles; and retirement. Second, the first two authors examined the content of these four codes for all the interviews and identified several subthemes. Third, these authors recoded the interview data within these subthemes, re-examined the meaning-units within the subthemes and mutually decided on three higher order themes: separateness and togetherness; negotiating roles; and negotiating intimacy. The data were summarized relative to these three themes. Finally, this analysis was reviewed by all four authors to ensure that the data had been accurately summarized. 


\section{Findings}

Our findings are presented in relation to the three higher order themes that emerged from the narrative analysis.

\section{Marriage as separateness and togetherness}

A major distinction between the Japanese and American couples is related to the way in which their marriages began. All of the Americans met their spouses and decided to marry by their own choice whereas most of the Japanese couples had had their marriages arranged by family members or a matchmaker. Following marriage, the American couples moved into their own residences while their Japanese counterparts moved in with extended family, often the husband's family.

Several of the Japanese wives spoke with intensity about the hardships endured during the early years of their marriage. They were responsible for cooking and caring not only for their husband and children but also for the husband's family of origin. In addition, they felt unsupported by their husbands whose loyalties were primarily devoted to the 'ie' (their extended families and ancestors) and to their work. For example, one couple lived with the husband's uncle; the young husband and wife had very little status in the family household. The husband described those early years in this way: 'I made my wife endure a very hard time during that period. And, it was especially hard as it was an arranged marriage where you feel the burden of household to household responsibility. If it was a free love marriage, it could be more supportable because you are both aware that you have freely chosen your couple life.'

Conceptions of marriage among the Japanese spouses related to separate spheres of influence, particularly in the early years of marriage. Husbands attended to their work while wives cared for the home and the family. In the words of one Japanese husband who had been employed as an engineer while his wife was a full-time housewife: 'I did nothing but a job. I didn't care anything about the family.' This understanding was echoed by a Japanese wife: 'In those days, everybody believed that men should devote themselves only to work ... we thought men should not do household tasks. That was thought to be shameful.' Such specialization in roles resulted in dependence on each other as expressed by another Japanese husband, a former carpenter: 'If she is not there. I cannot manage anything by myself.'

While this separation of roles and dependence on each other characterized most of our Japanese couples, there were a few exceptions. One of the couples was the product of a 'love match' and had worked together as shopkeepers since before their marriage. Their interdependence was exemplified by the way in which they shared domestic tasks. Even their dialogue reflected a pattern of helping each other to finish a thought:

Husband: ... as both of us are working, we don't have our own parts.

Wife: No.

Husband: To describe this morning...

Wife: When I was doing washing...

Husband: I was sweeping the floor over there.

Wife: Then we finished them together.

Husband: Yes, we finished them together. [Laughter]

This couple, whose overlapping responsibilities were atypical of the 
Japanese couples we interviewed, illustrates the influence of employment on patterns of interdependence over and above the effect of culture.

A quite different picture of marriage emerged among the American couples. While many of the American wives devoted themselves to caring for their children and homes in the early years of marriage, most returned to the labor force either before or after their children were grown. Among these American spouses - and especially among the wives - marriage was characterized as a partnership or team. One wife reflected on the early years of marriage when both she and her husband were employed and said: 'I think we worked in a very compatible team way.' An African-American wife who was the primary bread-winner for her family echoed this sentiment when discussing their current marital situation: 'We're a team. Nobody has the upper hand.' Another wife, who reluctantly stopped working when she married, spoke eloquently to the changes in interdependence in her marriage: 'I have to say that when we first married, I felt very dependent, very dependent ... I was dependent financially. I was dependent in every way on you. I think when we got children and I saw my role really expanded at that point and I felt we were more partners, that I had a part to play and you had a part to play. Then when the kids left home and I got a job, we were partners again in a different way. Then the last years of our life when I was working so hard and you were cutting back, I felt that the roles were reversed again. Now, again, we're back to being partners.'

A similar concept is expressed by one of the American husbands who spoke about his philosophy of marriage as togetherness: 'We all go down a single path. And once you're married, you converge and two have the same path. If you continue on two separate paths, it's not going to work.'

In contrast to the Japanese couples, there were frequent allusions among the American couples to themselves as 'we'. One American wife who had worked outside the house throughout the marriage talked about their problem-solving strategy earlier in their marriage: 'We would try to work things through together, discussing them.' An African-American wife described the couple's reaction when her husband had to give up his car: 'We miss drivin'.' One of the husbands talked about the couple's ambivalence over retirement plans: ' ... we didn't make up our minds to do that and then our minds got made up for us for awhile.' Comments about doing things together (e.g. shopping, cooking, taking classes) were peppered throughout the American couples' interviews.

The importance of interdependence and togetherness among the American spouses was evidenced most vividly by a couple who did not fit this image. This couple, who came to America from Great Britain during their early years of marriage, had retained quite distinct roles over the course of their marriage. When their children were born, the husband took on extra work so that they could afford to have the wife stay at home and raise the children. In retrospect, the husband acknowledged that he was 'a limited parent'. They both expressed regrets about the outcomes of their distinct roles. The husband said: 'In looking back you really need a balance. Separating the tasks has limitations because you lead separate lives.' His wife spoke about her feelings of emotional isolation and her longing for a different kind of marriage: 'He [her husband] never had this idea of mutual aid. It was my idea of marriage as sort of mutual aid, mutual dependence.' Although the role separation experienced by this couple was very similar to the one described by Japanese couples, their attitude was more similar to the American couples in that they idealized marriage as a relationship of partnership and togetherness. 


\section{Negotiating roles in marriage}

The couples we interviewed had negotiated their roles early within their marriages but frequently renegotiated these roles over time. Our Japanese and American samples used quite different rules to determine their roles. American couples were more likely to incorporate notions of equity into their conceptions of marital roles while the Japanese used rules of complementarity.

Within our American sample, a few couples provided especially vivid examples of the importance of equity within their marriages. The wife who had stayed at home to care for the children, and who longed for a relationship with more 'mutual aid' viewed her relationship in these terms: 'So along the way, it's been either I went along with his pursuit or I did something on my own, he didn't come with me. So there's been an inequality.' To the extent that couples' spheres of influence overlapped in the world of work, there was more opportunity for inequities to become apparent. Looking back on their working lives, a professional couple talked about the differences in their contributions to the family income. In this case, the husband was more aware of inequity than the wife.

Husband: There was a period of a few years, maybe three, when she was making more money than I was for the first time, and only time, in our existence.

Wife: You know, I was never aware of that.

Husband: Well, I was aware of it. I can't say that it really bothered me a whole lot, but obviously it did bother me some because I remembered it, you know.

Overlapping roles also occurred within the domestic realm, leading in some cases to greater awareness of inequity. One of the American wives who had returned to the labor force after her children were grown talked about how her husband had taken on some of the domestic tasks within the house. After retirement, his involvement in household tasks had further increased. His wife characterized their current distribution of labor as: 'He does very much more than his share.' While such inequities seemed to be negotiated with relative ease and good will by most of the couples, a few wives registered considerable discomfort concerning their husbands' increased involvement in household tasks. This discomfort appeared to be associated with a feeling that the husband was encroaching on their territory. One wife who typified this pattern referred to her husband as 'Mr Butt-in' when he took over the cooking responsibilities and expressed annoyance at him: 'You want to run my life. Like when you took over my kitchen, you take over this and you take over that and you aren't keeping your garage clean.' Another wife viewed her husband's desire to cook and sew, after retirement, as a threat to her marital contribution and her importance in the marriage, saying: 'I see these things as: Hey, you're through with me. I don't need you for anything.'

For the small subsample of three African-American couples, concerns about equity did not emerge as a salient issue. These couples had struggled to obtain and maintain their jobs. They emphasized the way in which they worked together and even substituted for each other when necessary. For example, one wife performed domestic labor with her husband and described their mutual support of one another at work: 'With the kinds of work we did, he had to wait tables. If I had a sick day or two, he'd carry on. He'd cook ... see working together meant a lot.'

The financial status of the African-American couples in our sample made work a necessity for both husbands and wives. However, the African-American 
women had experienced more job security than their husbands, who went in and out of the labor force. Their ability to negotiate a harmonious sharing of overlapping roles was evidenced at home as well as at work. One of the AfricanAmerican husbands who was now caring for his infirm wife focused very little on how much he was doing for her and, instead, highlighted their history of shared domestic roles: 'Well my wife and I always, when she'd be well, we work together. I wash dishes and she dry dishes. When we get ready to make the bed she get on one side and I get on the other. If I was running the sweeper, she would do the dusting or cleaning mirrors or something. We all work together doing anything like that.'

Like the African-American couples, equity did not appear to be a concept that Japanese spouses applied to their marriages. Instead, they highlighted their need for and dep mitence on each other relative to the performance of their distinct roles in the $x_{1}$,nded family. According to the husband who lived with his wife in his uncle's nousehold during their early marriage: 'Really I cannot do anything without her. If she is absent, I am in a real fix.' Even the previously mentioned shopkeepers, whose roles overlapped considerably at work, described their reliance on each other. Said the husband: 'She's why I have many fierds... She is good at cleaning, washing and cooking.' The wife's parallel response at one point in the interview was: 'He does everything for me.' At another point, she elaborated on how reliant she was on her husband to help negotiate the outside world: 'I just depend on him so I don't remember the way. That's my problem. I have always been taken and sent for, so I can't remember anything.'

Of particular interest among the Japanese couples was how this dependence on each other's roles was renegotiated over time. The most dramatic change was evidenced by the husbands as they assumed more domestic tasks in relation to their wives' health problems. In our Japanese sample, several of the wives were in frailer health than their husbands and, in such cases, the husbands assumed considerably more responsibility than they had in the past. One Japanese wife had been responsible for all the domestic tasks during the earlier part of their marriage, including caring for their children, her husband, her husband's students and the animals from his laboratory. Now that she was infirm and wheelchair-bound, their roles had switched dramatically. In the husband's words: 'She can't do anything without me now. So, I take care of her breakfast, lunch and supper and cook rice, then care of her body, then cleaning of our house and laundry. I studied a lot about cooking.'

\section{Negotiating intimacy in marriage}

In addition to negotiating role relationships, the couples we interviewed were also negotiating a balance between intimacy and distance in their marriages. In the American and Japanese samples, we saw evidence of struggles associated with wanting more or less closeness over time. A major theme that emerged among the Japanese couples was their enhanced enjoyment of togetherness and emotional intimacy over time, whereas among the American couples there emerged a desire for more space to pursue individual growth.

Due to their arranged marriages, the Japanese couples often started their lives together with very little knowledge of each other's personality or interests. Their crowded housing conditions and the expectations that they would maintain distinct roles all contributed to a sense of emotional distance. The wife who moved in with her husband's uncle's family eloquently portrayed her feelings 
towards her husband during their early years together: 'This life was not a real couple life. I did not feel that I was his partner. There wasn't any kind of passion or charm of love between us so that I came to suspect that maybe my husband had another woman outside. I needed from him some kind of love, even not a very big one but there was nothing such.'

On his part, her husband was carefully trying not to show any affection towards his wife lest he upset the existing balance of loyalties within the household and arouse jealousy towards his young wife. Several of the Japanese wives talked about yearning to leave their marriages during those early years. Of the 11 Japanese wives, five had considered divorce and one had thought of suicide.

Despite the emotional distance during the early years of marriage, there was ample indication of emotional closeness among the Japanese spouses in later life. One crucial ingredient of the change addressed by many of the Japanese couples was the husbands' capacity to show more nurturance of and affection to their wives. This change was summarized by one Japanese husband who viewed his marriage in two separate parts: 'In my case, the first half was a lot of problems. I don't know if it is because our way of doing things are completely different. It is stable at present but the first half was confusing.'

This increased intimacy appeared to be related to a number of factors. One factor, as previously mentioned, was the wife's poor health. Husbands who cared for their wives became more emotionally supportive. In the words of the wheelchair-bound wife whose husband had assumed all domestic tasks: 'He became a good father after he got old.' A second factor was the couples' changed status within the family as older members of the extended family died. One couple noted a marked freedom in their marital relationship when the husband's mother died. Now, in their later years, the husband could openly express his affection for his wife. He described this change by saying: 'My wife is now my treasure.' A third factor was the husband's increased awareness of how early role relationships and emotional distance had affected their wives. Several husbands expressed regrets about their early behavior and provided affirmations of their wives. One husband whose wife had cared for his extended family recalled: 'I really made her have a hard time.' Now, however, the wife had assumed a larger role in outside activities, which her husband respectfully acknowledged. A fourth factor was related to the belief that nurturance and support should evolve over time. One of the Japanese husbands illustrated this point by describing the marital philosophy to which he and his wife subscribed: 'Couples should not reveal themselves completely during their newlywed period. There must at least be something to be reserved for the future ... We shouldn't reveal all our good points to one another all at once; it has to be done slowly, little by little.'

In contrast to the Japanese couples' struggle for intimacy, many of the American spouses were actively involved in negotiating separateness from each other. In the words of the wife who had reluctantly retired after her husband: 'I have very consciously tried to have each of us have things that are ours.' Indeed, this need for a separate identity and space in which to develop autonomously was most frequently expressed by retired American women. One such wife spoke about the couple's decision to move to a larger apartment after she retired. She acknowledged that she had the capacity to completely absorb her husband. In her words: 'I could just be like a sponge.' She thought that the increased space in their larger apartment and his involvement in a separate hobby were a good antidote to becoming overly close. Another retired woman 
acknowledged that their house was larger than two people needed but: 'It's nice to have the space ... And I can be, we can be, in and out together. That's important.' Other retired couples discussed their decision to keep two cars so that they could maintain their independence. While American couples were clearly committed to togetherness, they had discovered that they enjoyed their times together more when they allowed each other distance.

\section{Discussion}

This qualitative study demonstrates the importance of including different voices and innovative methodologies in family development research. The narrative approach enabled couples with varied backgrounds to tell the story of their developing relationships. Findings from our study suggest that couples' interdependence is experienced in culturally specific ways. Further, role relationships and intimacy are often renegotiated over time. Here we highlight some of our most important discoveries relevant to family theory and provide suggestions for future research in this area.

One finding from our study is that interdependence among couples is expressed differently across cultures and between racial groups. Drawing from equity theory (Walster et al., 1978), previous research on older American couples has placed considerable emphasis on the importance of equitable role exchanges in the marital relationship (Ingersoll-Dayton \& Antonucci, 1988; Keith et al., 1992; Ward, 1993). In our interviews, we found further evidence of the importance of this concept among older white American couples. However, equity in role exchanges was not discussed by African-American and Japanese couples. Instead, the Japanese couples emphasized complementary interdependence in which spouses had quite distinct roles so that mutually dependent exchanges rather than equitable exchanges were emphasized. The African-American couples highlighted interchangeable interdependence in which either spouse could assume the other's role, if necessary.

Bolstering the cultural differences in spousal roles that we observed, a cross-national study that included older Japanese and Americans found that only 5 percent of Japanese interviewees thought husbands should share chores equally with their wives after retirement, compared with 60 percent of Americans (Policy Office for the Aged, 1991). When couples have such distinct areas of responsibility they must rely on complementary rather than equitable involvement within the same spheres of influence.

Other scholars have also addressed the connection between culture and complementarity of spousal roles. For example, Lebra (1984: 300) points out how the public domains of Japanese society depend upon separate roles: 'Companies expect their employees to be looked after by their homebound wives so that they, the husbands, will maintain their dedication to the companies'. According to Edwards (1989), this notion is ingrained in the Japanese view of the individual and the family. The Japanese view the individual as incomplete, he says, and unable to function in society alone, 
needing the structure of the family unit to be complete. Edwards describes (1989: 116) the distinct gender roles within Japanese couples as constituting a 'complementary distribution of both competencies and incompetencies'. Indeed, among the Japanese couples we interviewed, a description by one spouse of his/her own incompetence appeared to be a way of affirming the competency of the other spouse.

Addressing the racial differences in spousal roles that we observed, a national probability sample of African-Americans found that a large majority of the older married respondents believed that they provided and received an equal amount in their relationship (Taylor et al., 1993). Many older African-American couples have experienced societal prejudice, resulting in difficulty with finding and keeping employment. Among our interviewees it was generally the African-American wives who maintained their jobs more easily than their husbands and who were sometimes responsible for finding work for their husbands. This flexibility in work roles may influence flexibility in domestic roles among African-Americans (Davis \& Proctor, 1989) that, in turn, contributes to a focus on interchangeable rather than equitable interdependence.

A second finding from our study is that feelings of intimacy and distance are renegotiated by couples over time. Unlike Blood's (1967) classic comparison of younger Japanese and American marriages, we saw little evidence of progressive disenchantment among our sample of long-term marriages. Instead, several life transitions emerged as important turning points in the couples' feelings of closeness. While couples from both cultures spoke about the same transitions, some turning points appeared to be more culturally salient than others.

A life transition that was an especially important precipitant of intimacy changes among Japanese couples was the loss of other close family members. The mother-son relationship, for example, is a particularly strong tie in Japanese families (Dore, 1978). When this tie is severed through death, the couple's relationship can change dramatically. Lebra (1984: 255) points out that: 'an aloof husband may be converted into an affectionate one ... when his mother dies'.

A life transition that influenced intimacy, particularly for the American couples in which both spouses were employed, was retirement. While many American spouses emphasized the importance of companionship within their marriage, they also asserted the need to balance time together with individual time. Several of the American spouses consciously planned to maintain their independence via separate cars and separate hobbies. Intimacy and distance were not, however, seen as dichotomous. Rather, for these couples, time apart was perceived as a way of enhancing their intimacy.

In both countries, a life transition that contributed to intimacy changes was the poor health of a spouse. However, changes in intimacy were most notable among the husbands whose wives were ill, especially the Japanese husbands. When their wives were no longer able to function within their former roles, the separate spheres of influence became blurred. Consistent with Gutmann's (1987) view of gender-related psychological changes that 
occur with age, husbands in our sample demonstrated more nurturance toward their wives during the later years of their marriage, especially when their wives were in poor health.

Taken together, our findings suggest that family development theory must account for inter-cultural as well as intra-cultural differences in the ways in which couples view their role exchanges. For example, while equity theory may help explain the rules of role distribution among older white American couples, it seems less relevant to the experience of older Japanese and African-American couples. In addition, our findings address the importance of examining life transitions throughout the couple's life cycle. Some transitions, such as the death of family members, emerge as more important for one culture than for another. We must continue to expand our theoretical formulations of family development to incorporate intra- and inter-cultural differences and recognize the crucial role of life transitions throughout the life cycle.

Findings from this study should be considered within the limitations of our research. This was an exploratory study designed to discover the salient aspects of couples' experience over the life course. Ours was a small, nonprobability sample. Future research in this area should be drawn from larger, representatively drawn samples to determine whether the different patterns we identified remain consistent. Further, we relied on couples' retrospective memories and the joint narrative of their experience over time. Additional research of a longitudinal nature could follow couples over time. Such research might also interview spouses independently to determine their individual views of their own and the couple's development. Moreover, the storyboard was based on previous work in the US and was selected for its cross-cultural relevance but may not fully capture the key life events most salient to Japanese couples. Future research efforts should address the cross-cultural validity of this narrative tool.

Examining the narratives of older couples offered a rich method for exploring development over the life course. Comparing the narratives of older Japanese and American couples gave us a window into how couples perceive and evaluate their relationships over time. A central focus for future investigation should be on examining marital diversity within cultures with particular attention to race, rural/urban and socioeconomic status differences. Finally, while our study focused primarily on couples who were happily married, it is important to know more about older couples who are dissatisfied with their marriages. Enquiring about the experience of such couples would increase our knowledge about family development and enhance our ability to help couples who experience difficulty negotiating transitions over the life course.

\section{REFERENCES}

Berger, P. \& Kellner, H. (1964) 'Marriage and the Construction of Reality', Diogenes 46: 1-24. Blood, R.O. (1967) Love Match and Arranged Marriage: A Tokyo-Detroit Comparison. New York: Free Press. 
Brubaker, T.H. (1985) 'Responsibility for Household Tasks: A Look at Golden Anniversary Couples Aged 75 Years and Older', in W. Peterson \& J. Quadagno (eds) Social Bonds in Later Life. Beverly Hills, CA: Sage.

Butler, R. (1980-81) 'The Life Review: An Unrecognized Bonanza', Journal of Aging and Human Development 12: 35-8.

Coward, R.T., Horne, C. \& Dwyer, J.W. (1992) 'Demographic Perspectives on Gender and Family Caregiving', in J.W. Dwyer \& R.T. Coward (eds) Gender, Families and Eldercare. Newbury Park, CA: Sage.

Davis, L.E. \& Proctor, E.K. (1988) Race, Gender and Class. Englewood Cliffs, NJ: PrenticeHall.

Dore, R.P. (1978) Shinohata: A Portrait of a Japanese Village. New York: Pantheon Books.

Edwards, E. (1989) Modern Japan Through its Weddings. Stanford, CA: Stanford University Press.

Gilford, R. (1986) 'Marriages in Later Life', Generations 10: 16-20.

Gutmann, D. (1987) Reclaimed Powers. New York: Basic Books.

Heath, S.B. (1983) Ways with Words: Language, Life, and Work in Communities and Classrooms. New York: Cambridge University Press.

Ingersoll-Dayton, B. \& Antonucci, T.C. (1988) 'Reciprocal and Nonreciprocal Social Support: Contrasting Sides of Intimate Relationships', Journal of Gerontology 43: S65-73.

Iwao, S. (1993) The Japanese Woman: Traditional Image and Changing Reality. Cambridge, MA: Harvard University Press.

Keith, P.M., Wacker, R.R. \& Schafer, R.B. (1992) 'Equity in Older Families', in M. Szinovacz, D.J. Ekerdt \& B.H. Vinick (eds) Families and Retirement. Newbury Park, CA: Sage.

Kono, S. (1994) 'Demographic Aspects of Population Aging in Japan', in S. Yoshida (ed.) Aging in Japan. Tokyo: Japan Aging Research Center.

Kumagai, F. (1984) 'The Life Cycle of the Japanese Family', Journal of Marriage and the Family 46: 191-204.

Kuypers, J. \& Bengtson, V.L. (1990) 'Toward Understanding Health in Older Families Impacted by Catastrophe', in T. Brubaker (ed.) Family Relationships in Later Life. Newbury Park, CA: Sage.

Lebra, T.S. (1984) Japanese Women: Constraint and Fulfilment. Honolulu: University of Hawaii Press.

Policy Office for the Aged, Management and Coordination Agency (1991) The International Study on Living and Consciousness of Elderly People, An Outline of the Results. Tokyo.

Riessman, C.K. (1993) Narrative Analysis. Newbury Park, CA: Sage.

Schick, F.L. \& Schick, R. (1994) Statistical Handbook on Aging Americans. Phoenix, AZ: Oryz Press.

Seidel, J., Kjolseth, R. \& Seymour, E. (1988) The Ethnograph. Littleton, CO: Qualis Research Associates.

Sherman, E. (1991) Reminiscence and the Self in Old Age. New York: Springer.

Taylor, R.J. Keith, V.M. \& Tucker, M.B. (1993) 'Gender, Marital, Familial, and Friendship Roles', in J. Jackson, L. Chatters \& R.J. Taylor (eds) Aging in Black America. Newbury Park, CA: Sage.

Veroff, J., Sutherland, L., Chadiha, L. \& Ortega, R.M. (1993) 'Newlyweds Tell Their Stories: A Narrative Method for Assessing Marital Experiences', Journal of Social and Personal Relationships 10: 437-57.

Walster, E., Walster, G.W. \& Berscheid, E. (1978) Equity: Theory and Research. Boston, MA: Allyn \& Bacon.

Ward, R.A. (1993) 'Marital Happiness and Household Equity in Later Life', Journal of Marriage and the Family 55: 427-438.

Watanabe, S. (1993) 'Cultural Differences in Framing: American and Japanese Group Discussions', in D. Tannen (ed.) Framing in Discourse. Oxford: Oxford University Press.

Yuzawa, Y. (1994) About Japan Series: Japanese Families. Tokyo: Foreign Press Center. 